\title{
Bacteriocyte dynamics during development of a holometabolous insect, the carpenter ant Camponotus floridanus
}

\author{
Sascha Stoll ${ }^{1,3}$, Heike Feldhaar ${ }^{2}$, Martin J Fraunholz ${ }^{1}$, Roy Gross ${ }^{1 *}$
}

\begin{abstract}
Background: The carpenter ant Camponotus floridanus harbors obligate intracellular mutualistic bacteria (Blochmannia floridanus) in specialized cells, the bacteriocytes, intercalated in their midgut tissue. The diffuse distribution of bacteriocytes over the midgut tissue is in contrast to many other insects carrying endosymbionts in specialized tissues which are often connected to the midgut but form a distinct organ, the bacteriome. $C$. floridanus is a holometabolous insect which undergoes a complete metamorphosis. During pupal stages a complete restructuring of the inner organs including the digestive tract takes place. So far, nothing was known about maintenance of endosymbionts during this life stage of a holometabolous insect. It was shown previously that the number of Blochmannia increases strongly during metamorphosis. This implicates an important function of Blochmannia in this developmental phase during which the animals are metabolically very active but do not have access to external food resources. Previous experiments have shown a nutritional contribution of the bacteria to host metabolism by production of essential amino acids and urease-mediated nitrogen recycling. In adult hosts the symbiosis appears to degenerate with increasing age of the animals.

Results: We investigated the distribution and dynamics of endosymbiotic bacteria and bacteriocytes at different stages during development of the animals from larva to imago by confocal laser scanning microscopy. The number of bacteriocytes in relation to symbiont-free midgut cells varied strongly over different developmental stages. Especially during metamorphosis the relative number of bacteria-filled bacteriocytes increased strongly when the larval midgut epithelium is shed. During this developmental stage the midgut itself became a huge symbiotic organ consisting almost exclusively of cells harboring bacteria. In fact, during this phase some bacteria were also found in midgut cells other than bacteriocytes indicating a cell-invasive capacity of Blochmannia. In adult animals the number of bacteriocytes generally decreased.

Conclusions: During the life cycle of the animals the distribution of bacteriocytes and of Blochmannia endosymbionts is remarkably dynamic. Our data show how the endosymbiont is retained within the midgut tissue during metamorphosis thereby ensuring the maintenance of the intracellular endosymbiosis despite a massive reorganization of the midgut tissue. The transformation of the entire midgut into a symbiotic organ during pupal stages underscores the important role of Blochmannia for its host in particular during metamorphosis.
\end{abstract}

\section{Background}

Bacteriocyte endosymbiosis is a widespread phenomenon in insects with an estimated 15 to $20 \%$ of all insects harboring obligate intracellular endosymbionts [1]. These socalled primary endosymbionts are harbored in specialized

\footnotetext{
* Correspondence: roy@biozentrum.uni-wuerzburg.de

'Lehrstuhl für Mikrobiologie, Biozentrum, Universität Würzburg, D-97074

Würzburg, Germany

Full list of author information is available at the end of the article
}

cells, the bacteriocytes, as well as in the reproductive tissues to facilitate maternal transmission. Accordingly, they are generally transmitted vertically and show a long history of strict co-evolution with their hosts [2,3]. Bacteriocytes can aggregate and form bacteriomes, organ-like structures in the body cavity of the insect host. Such bacteriomes are frequently associated with the midgut, such as in aphids or tsetse flies, or the fat body as in cockroaches [2,3]. Bacteriocytes can also be found interspersed among cells of host
Ciomed Central

() 2010 Stoll et al; licensee BioMed Central Ltd. This is an Open Access article distributed under the terms of the Creative Commons Attribution License (http://creativecommons.org/licenses/by/2.0), which permits unrestricted use, distribution, and reproduction in any medium, provided the original work is properly cited. 
tissues, e.g. within the midgut tissue of carpenter ants, where they are intercalated between midgut cells $[4,5]$. Within the bacteriocyte the bacteria can either be surrounded by a host derived symbiosomal membrane, e.g. Buchnera in aphids $[2,6]$, or they reside in the cytoplasm, e.g. Blochmannia in ants [5]. Generally, these bacteria are confined to intracellular locations, although, for instance, Wigglesworthia, the primary endosymbiont of tsetse flies, can also be found extracellularly in the milk gland lumen from where the bacteria can infect the developing brood [7]. In contrast to primary endosymbionts, invasion of different tissues is observed frequently for secondary endosymbionts which are not essential for the animals [8]. Early observations indicated that Blochmannia may also have a cell invasive capacity, when the bacteria evade from bacteriocytes in the midgut tissue in order to infiltrate the oocytes thus guaranteeing the vertical transmission of the bacteria [9].

Bacteriocyte endosymbionts are frequently observed in animals with a specialized diet lacking nutrients essential for the animals such as aphids or tsetse flies feeding exclusively on plant sap or blood, respectively [10]. There is ample evidence that these mutualists contribute to host nutrition by supplementing the host's diet with, for example, essential amino acids in the Buchneraaphid endosymbiosis or vitamins in the Wigglesworthiatsetse fly interaction. In contrast, ants of the genus Camponotus and related genera such as Polyrhachis harboring endosymbiotic Blochmannia are generally considered to be omnivorous [11]. However, ants are often limited by nitrogen availability, especially in habitats that are generally poor in nitrogen compounds such as tropical rain forest canopies [12]. Blochmannia encodes a functional urease and glutamine synthetase and may therefore be involved in nitrogen recycling. Recently, it was shown that Blochmannia upgrades the diet of individual ants by the synthesis of essential amino acids. This is probably also relevant on the colony level by improving the quality of food provided to larvae by care-taking young workers which feed the larvae by trophallaxis $[13,14]$. Ants are holometabolous animals and these metabolic capabilities of the endosymbiont may be of particular relevance during metamorphosis when the animals are excluded from external food resources. In line with this assumption, massive replication of the bacteria and an upregulation of amino acid biosynthesis genes and urease were observed in particular during pupal stages [14-16].

Very little is known about the cell biology, developmental origin and evolution of bacteriocytes. A general characteristic of such cells appears to be a high degree of polyploidy, possibly reflecting the high metabolic output of these cells [17-20]. The ontogeny of bacteriocytes to date was investigated only in early developmental stages of hemimetabolous aphids, which can reproduce parthenogenetically. The endosymbiotic bacteria are transmitted directly from mother to developing embryos in the blastoderm stage. A two-step recruitment of bacteriocytes was observed in the aphid Acyrthosiphon pisum using bacteriocyte specific markers. Bacteriocytes are developed before transmission of maternal bacteria to the aphid embryo and a second population of cells is transformed into bacteriocytes later in development [21]. Nevertheless, in aphid lineages that have secondarily lost the symbiotic bacteria the bacteriocytes were either maintained or their development was initiated but then aborted [21]. The number of Buchnera in A. pisum may be actively downregulated by the host about two weeks after final ecdysis. The decrease in symbiont number was shown to be correlated with an activation of the lysosomal system of the bacteriocytes $[22,23]$.

Recently, it was shown that in larvae of the holometabolous olive fly Bactrocera oleae the vertically inherited endosymbiont Candidatus Erwinia dacicola is located intracellularly within midgut cells. After metamorphosis, however, the bacteria have an extracellular location in the foregut. It was consequently suggested that this change in the endosymbiont's location and lifestyle may be related to host metamorphosis [24]. Extracellular endosymbionts residing in the digestive tract of an insect, for example the complex gut microflora of the hemimetabolous termites, are lost with every molting. However, termites much alike ants are social insects and it is thought that behavioral strategies such as trophallaxis or coprophagy allow the vertical transmission of the endosymbiotic community via nutritional exchange between individuals of the termite colony [25].

In previous studies based on light or electron microscopy the distribution of $B$. floridanus containing bacteriocytes during larval and adult stages of its host C. floridanus was investigated $[4,5,26]$. Bacteriocytes were found to have an island-like distribution in the midgut tissue in both life stages examined. So far, the fate of the bacteriocytes and their bacterial inhabitants during pupal stages and the mechanisms of how the symbionts are maintained throughout metamorphosis have not been investigated. At the onset of metamorphosis of holometabolous insects the entire inner larval gut epithelium including the gut content is shed and excreted [27], becoming visible as the meconium (a dark spot at the distal pole of early stage pupae; see below). The epithelial cells are removed by apoptosis and autophagy and their nutrients are reabsorbed by the pupal gut epithelium [27]. Nonetheless, in C. floridanus the number of bacteria present in the host constantly increases from larval over pupal stages towards adult workers [15]. 
Here, we investigated how the symbiosis between the holometabolous ant $C$. floridanus with its primary endosymbiont $B$. floridanus is maintained during metamorphosis. We used fluorescence in-situ hybridization (FISH) and direct fluorescence labeling of the bacteria to study the fate of Blochmannia and its host cells during larval, pupal and adult life stages of the host.

\section{Results and Discussion}

\section{Bacteriocyte distribution in larvae of $C$. floridanus}

The distribution of endosymbiont containing bacteriocytes within the host midgut tissue was investigated by FISH and direct fluorescence labeling of bacteria and host cells over different developmental stages. We stained Blochmannia with a $16 \mathrm{~S}$ rRNA specific greenfluorescent oligonucleotide (Bfl172-FITC) and host cells with red-fluorescent SYTO Orange 83 and fluorescence was detected by confocal laser scanning microscopy (CLSM). Figure 1A shows the midgut of L1 larvae at $10 \times$ magnification. Panels B-E show orthogonal views of different optical sections of the image stack of midgut tissue. The Z-positions of the optical midgut sections are indicated by blue lines in the $X Z$ and $Y Z$ views below and right of each $X Y$ section representation, respectively. The midgut lumen (Figure 1B-E, white arrows) is visible as a continuous space encased by bacteria-free cells. Bacteriocytes can easily be distinguished from other cell types by the densely packed greenfluorescent bacterial mass they contain as well as the relatively small size of their nuclei $(\varnothing 5-8 \mu \mathrm{m})$ in comparison to the large nucleoli-rich nuclei $(\varnothing 10$ $>30 \mu \mathrm{m}$ ) of other midgut cells (Figure 1D; blue arrows). Overall, the analysis of L1 larvae showed that the outer layer of the midgut epithelium comprises largely bacteriocytes, a feature which was also found in a previous in situ hybridization study [4]. In contrast, optical sections close to the gut lumen showed an absence of bacteriocytes from the epithelial layer lining the midgut lumen (Figure 1D-E).

In the last instar larvae (L2) the spatial pattern of bacteriocyte distribution in relation to epithelial cells changed: the nearly contiguous bacteriocyte layer building up the outer layer of the midgut tissue present in stage L1 is broken up (Figure 2A). Thus, a characteristic feature of this stage is the presence of scattered bacteriocyte islands in the outer layer of the midgut tissue and a large number of bacteriocytes intercalated between bacteria-free midgut cells. As in the case of L1 larvae no bacteriocytes were found in the epithelial layer lining the gut lumen (Figure 2D-E). This distruption of the layer of bacteriocytes may be due to a strong increase in the size of the gut due to a proliferation of the epithelial cells lining the gut lumen. The same island-like distribution of bacteriocytes has been observed previously in L2 larvae by in situ hybridization [4] and could also be seen after staining of actin fibres, which are part of the muscle network surrounding the gut tissue. In these preparations stained clusters of bacteriocytes were visible directly underneath the muscle network enclosing the midgut (Figure 3).

\section{Bacteriocyte dynamics during metamorphosis}

In early pupal stage 1 prior to the shedding of the remnants of larval midgut tissue and meconium formation, the distribution of bacteriocytes was still island-like as observed in L2 larvae (Figure 4). This is in accordance with recent results, showing that the number of bacteria is relatively stable between these two developmental stages [15]. However, in the late P1 stage there was a massive increase in the number of bacteriocytes relative to epithelial cells resulting again in a nearly contiguous layer of these cells enclosing the epithelial cells lining the midgut lumen (Figure 5). In P1 pupae we also observed cells harboring bacteria that do not resemble typical bacteriocytes due to the larger size of their nuclei and the frequent presence of SYTO-stained vesicles (Figure 5D, E), possibly suggesting bacterial invasion in otherwise bacteria-free enterocytes (see below). The pupal stage 2 is characterized by the shedding of the remnants of larval gut tissue and excretion of the meconium and, consequently, by an alteration of the structure of the midgut (Figure 6). Astonishingly, at this stage virtually all cells were harboring bacteria. Symbionts appeared to be present mainly in bacteriocytes, but, once more, some enterocytes with large nuclei appeared to harbor Blochmannia (Figure 6E). Thus, in contrast to larval stages, virtually all cells of the layer lining the gut lumen contained bacteria. With nearly the whole tissue being formed by bacteria-harboring cells the entire midgut can be viewed as symbiotic organ resembling the organ-like bacteriomes of aphids and tsetse flies. This was paralleled by an increase in the absolute number of Blochmannia harbored per host [15]. In pupal stage 3 shortly before eclosion bacteriocytes still were the dominating cell type of the midgut, but within the dense bacteria-harbouring midgut tissue again some bacteria-free cells started to appear (Figure 7).

\section{Bacteriocyte distribution in adult animals}

Young imagines directly after eclosion showed a very similar midgut structure as P3 pupae, although the proportion of bacteria-free cells with large nuclei was increasing (Figure 8). Previously, it was reported that with increasing age the symbiosis appears to degenerate and the number of symbionts strongly decreases. This decrease in symbiont and bacteriocyte numbers was shown for $C$. floridanus queens and workers, but also 

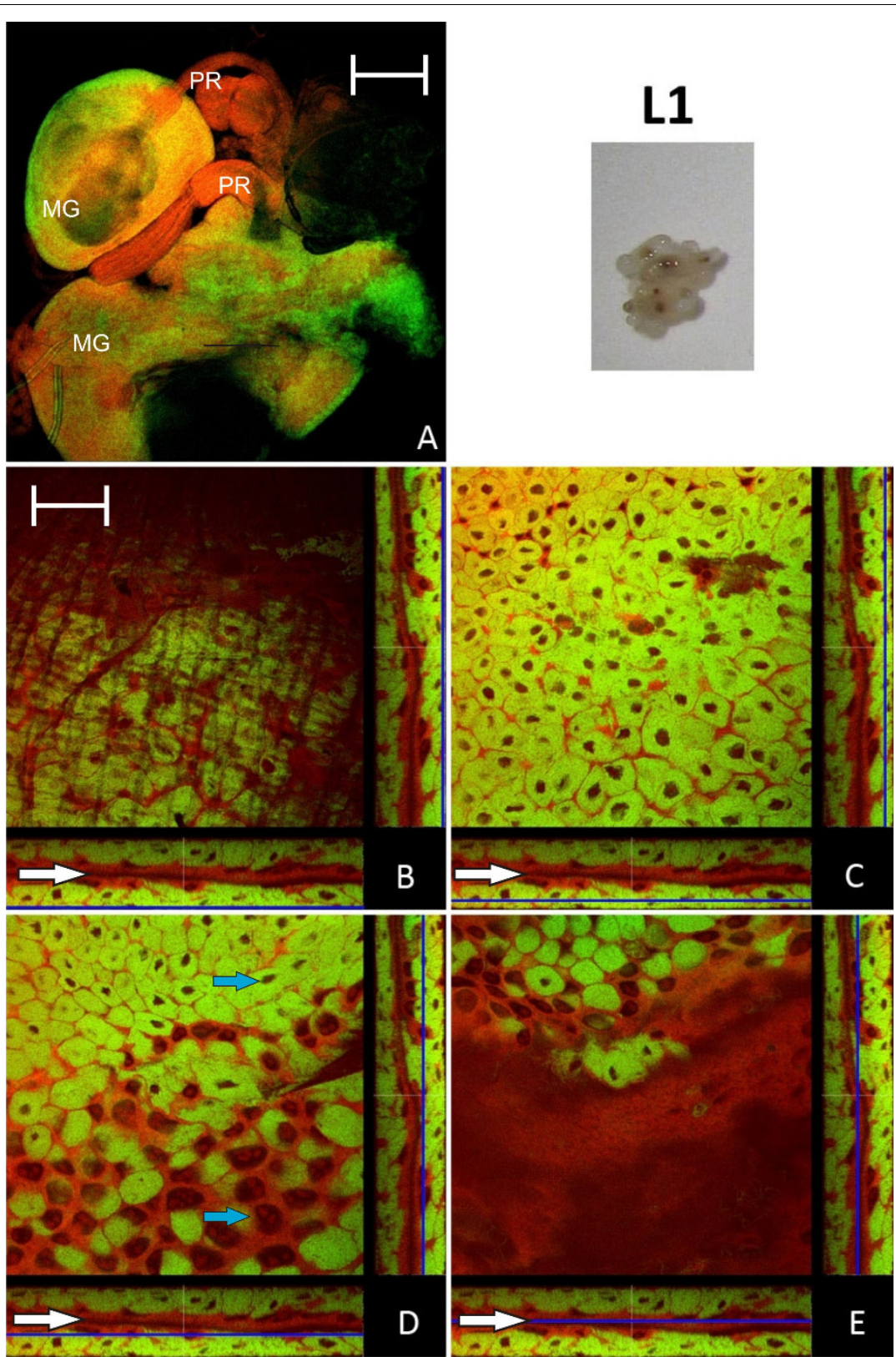

Figure 1 Larva of stage L1. A: Overview showing two midguts (MG) and their proventriculi (PR) by confocal laser scanning microscopy. B - E: Four orthogonal views of confocal image stacks of C floridanus L1 larva midgut sections. The blue lines in the XZ and YZ stack representations (below and on the right side of each quadratic micrograph) illustrate the position of the image plane (XY). The bacteria-free midgut cells typically have large nuclei and several nucleoli while the bacteriocytes are characterized by small nuclei (blue arrows in D). The bacteriocytes form a nearly contiguous layer surrounding the midgut $(B, C)$ directly underneath of the muscle network ( $A$ and Fig. 3). There are no bacteriocytes present in the cell layer lining the midgut lumen $(D, E)$. The midgut lumen is indicated by white arrows. Green label: The Blochmannia specific probe Bfl172-FITC; red label: SYTO Orange 83. The scale bars correspond to $220 \mu \mathrm{M}(\mathrm{A})$ and $35 \mu \mathrm{M}(\mathrm{B}-\mathrm{E})$, respectively.

for workers of C. sericeiventris $[4,15,16]$. The confocal analysis carried out in this study confirmed these findings. However, the situation in workers older than 6 months is quite heterogeneous with regard to bacteriocyte distribution among individuals. In general, as expected, the ratio of bacteriocytes decreases and the midgut structure resembled that of larvae with bacteriocytes being intercalated between midgut cells close to the basal membrane. However, in some of the animals there were still plenty of bacteriocytes present, while in others the symbiosis degenerated dramatically and only very few bacteriocytes dispersed in the midgut tissue 


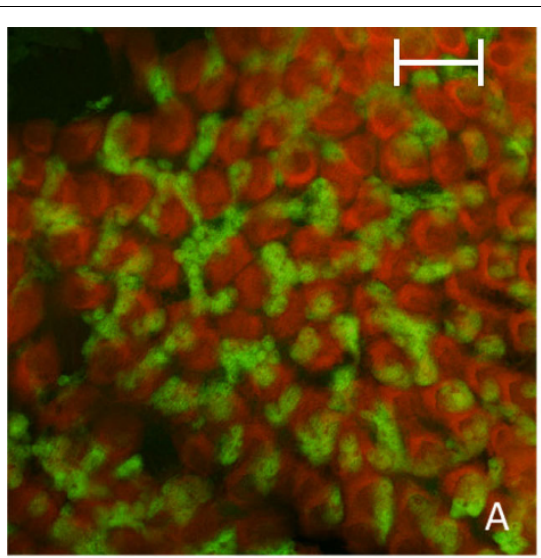

\section{L2}

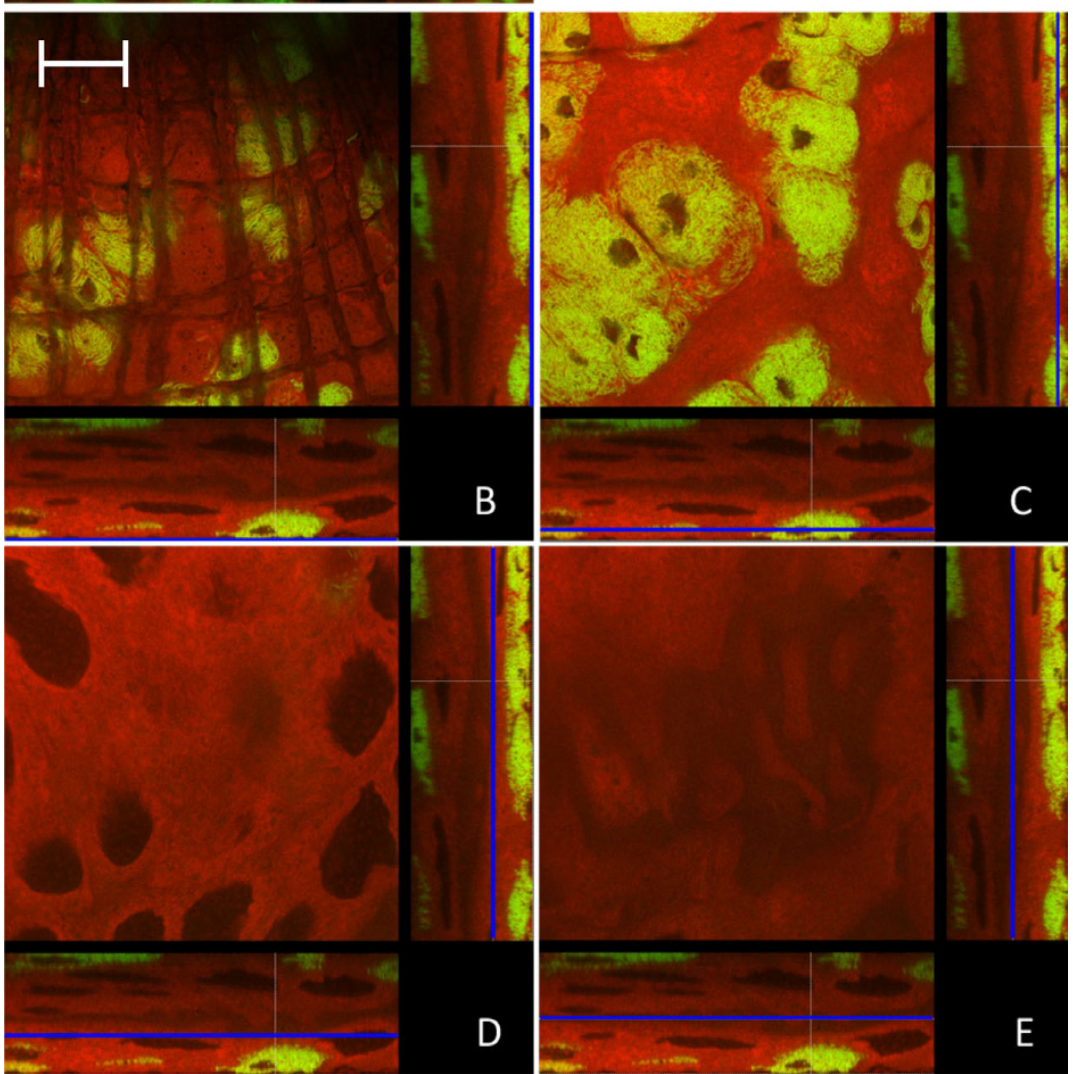

Figure 2 Larva of stage L2. Overview (A) and detailed images of different optical sections (B - E) of the midgut of a C. floridanus larva (L2) by confocal laser scanning microscopy (for further information regarding the composition of the figure see legend of Fig. 1). The bacteriocytes are located in cell clusters of different size on the outer surface of the midgut $(B, C)$ and the cells lining the midgut lumen are free of bacteria (D, E). Green label: The Blochmannia specific probe Bfl172-FITC; red label: SYTO Orange 83. The scale bars correspond to $220 \mu \mathrm{M}(\mathrm{A})$ and $35 \mu \mathrm{M}(\mathrm{B}-\mathrm{E})$, respectively.

could be observed (Figure 9, 10). An illustration of the results described above is presented in Figure 11 which shows schematic drawings of the different developmental stages and the distribution of bacteriocytes therein.

Males are an evolutionary dead end for the bacteria since they cannot be transmitted to the progeny via the spermatocytes [4]. Nonetheless, just as the females, the males may require the endosymbionts for proper development during early life stages. We observed that the distribution of bacteriocytes during developmental stages of males (derived from unfertilized worker eggs) was very similar to that of workers including the fact that the midgut of late pupae was nearly entirely composed of bacteria-harboring cells (data not shown).

Changes in the relative bacterial population density in the midgut tissue of different developmental stages were 

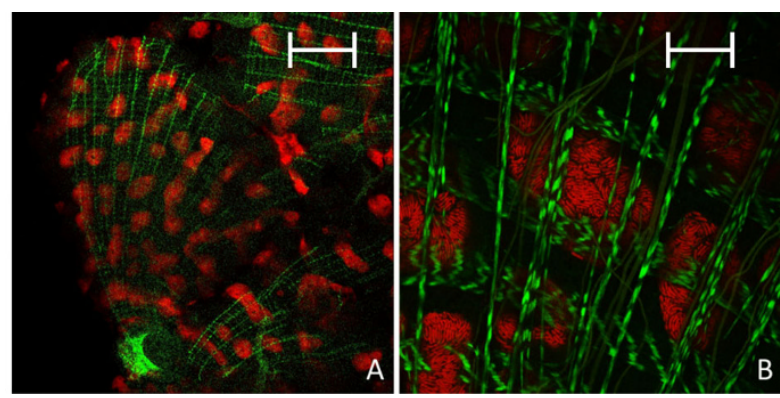

Figure 3 Overview (A) and detailed image (B) of the actinstained muscle network surrounding the midgut of a $B$. floridanus larva (L2) by confocal laser scanning microscopy. Green label: FITC-Phalloidin; red label: The Blochmannia specific probe $\mathrm{Bfl} 172-\mathrm{Cy} 3$. The scale bars correspond to $220 \mu \mathrm{M}(\mathrm{A})$ and $35 \mu \mathrm{M}(\mathrm{B})$, respectively.

quantified as described in the Methods section (Figure 12). Volume fractions differed significantly among groups (ANOVA: $\mathrm{p}<0.001, \mathrm{~F}=13.08$, $\mathrm{df}=7$ ). The results are in perfect agreement with the optical evaluation described above showing a high proportion of bacteriocytes in L1 $(40.84 \pm 8.75)$, when a contiguous bacteriocyte layer is surrounding the midgut (Figure 1). Volume fractions were significantly reduced in comparison to all other developmental stages both in L2 (13.25 $\pm 4.78)$ and early P1 pupae $(17.63 \pm 10.66)$ when the bacteriocytes have an island-like distribution in the outer layer of the midgut directly underneath of the muscle network due to growth of the midgut tissue in this stage (Figure 2, Figure 3). Also, in older animals the number of bacteriocytes is strongly decreased (29.41 \pm 5.51 and $16.44 \pm 10.83$ for W3-1 and W3-2, respectively; due to small sample size, W3-1 was excluded from ANOVA). The fraction of Blochmannia-infected midgut tissue is significantly increased in developmental stages around metamorphosis from late P1 pupae (and 48.34 \pm 11.38 ) to young workers directly after eclosion (W1: $55.04 \pm 9.58$ ) (Figure 12).

\section{Presence of Blochmannia in midgut cells other than bacteriocytes}

As stated above, some Blochmannia may also be found in cells other than bacteriocytes, although the number of bacteria inside these cells appeared to be much lower than in regular bacteriocytes (Figure 5D,E, Figure 6C). The appearance of bacteria-bearing cells not resembling typical bacteriocytes due to their large nuclei was most prominent in pupae around metamorphosis, but occasionally they could also be seen in other developmental stages (Figure 5DE, Figure 10C). An interesting characteristic of such cells was that, frequently, they harbored a much large number of SYTO-stained vesicles than bacteriocytes (Figure 5E). Thus, Blochmannia may have the capacity to actively invade into other cell types within the midgut tissue. In agreement with these findings, Blochmannia was detected occasionally in midgut cells not resembling bacteriocytes in males of $C$. floridanus and $C$. herculeanus in a previous study [4]. In the cockroach Blattella germanica its primary endosymbiont (belonging to the Bacteroidetes) is harbored in bacteriocytes lining the fat body. In B. germanica it was observed that in nymphal instars the increase in the number of bacteriocytes was not sufficient to explain the strong increase in the number of cells containing endosymbionts. Thus, it was suggested that in these stages bacteria may have invaded fat body cells other than bacteriocytes [28].

Future work must elucidate the nature of these vesiclecontaining cells and whether the vesicles may be directly related to the presence of the endosymbionts. It is possible that the observed vesicles are derived from the lysosomal system and may indicate digestion of some bacteria during metamorphosis and during adult stages when the symbiosis degenerates. A similar phenomenon was recently reported for aphids harboring the endosymbiont Buchnera within their characteristic symbiosomal vacuoles in bacteriocytes. In these animals about two weeks after ecdysis the bacterial load decreases strongly. A cytochemical analysis revealed the presence of lysosome-like acidic organelles in the bacteriocytes and an upregulation of lysosome-related genes around final ecdysis [22,23]. Electron microscopic analysis of the aphid tissue in these stages revealed a different morphology of the symbiosomes, suggesting degradation of the endosymbionts by the lysosomal system. Digestion of endosymbionts in older ant workers may be reasonable, since the symbiosis does not appear to be of much role in these animals anymore. In fact, in a previous study in C. sericeiventris workers Blochmannia was occasionally found within vacuoles of host cells [16]. Autophagocytic processes may also be involved in the control of the endosymbiont number keeping it in balance with the host's needs and developmental stages [29].

\section{Effect of antibiotics treatment on the midgut}

Aposymbiotic animals can be obtained by feeding antibiotics to workers or queens. The treatment of queens should reduce the number of endosymbionts transmitted to the next generation via the egg, whereas workers transfer antibiotics directly to the developing larvae via trophallaxis. The breeding success in a colony of an aposymbiotic queen is strongly reduced, but a diet containing all nutrients needed by the brood can counteract the deleterious effect of symbiont loss to some extent $[13,14]$. Thus, a limited number of aposymbiotic larvae and pupae can be obtained. In none of the investigated larvae and pupae derived from a rifampicin treated queen symbionts could be detected. Nonetheless, in 

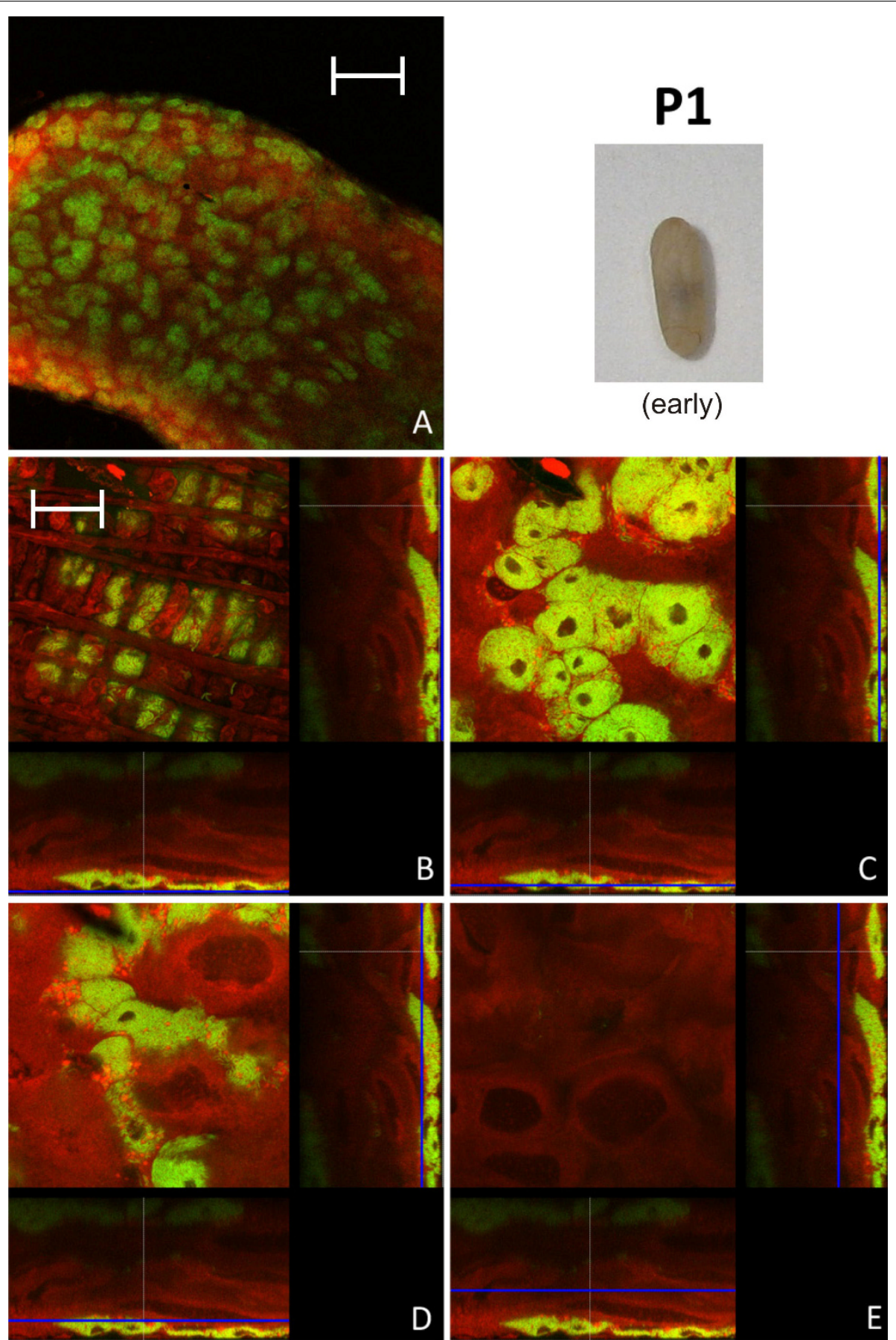

Figure 4 Early stage P1 pupa. Overview (A) and detailed images of different optical sections (B - E) of the midgut of a C. floridanus pupa (P1) prior to excretion of the meconium by confocal laser scanning microscopy (for further information regarding the composition of the figure see legend of Fig. 1). The distribution of bacteriocytes resembles that of L2 larvae shown in Fig. 2. Green label: The Blochmannia specific probe Bfl172-FITC; red label: SYTO Orange 83. The scale bars correspond to $220 \mu \mathrm{M}(\mathrm{A})$ and $35 \mu \mathrm{M}(\mathrm{B}-\mathrm{E})$, respectively.

these animals cells characterized by small nuclei $(\varnothing 5$ $8 \mu \mathrm{m})$ were found in small clusters of up to 10 cells in the outer layer of the midgut. Based on their small nuclei these cells likely represent empty bacteriocytes (Figure 13). This suggests that, as already shown for aphids [21], the bacteriocytes are formed as part of the normal developmental program of the ant hosts and their generation does not need any bacterial stimulus. However, further analysis is required to unambiguously identify the nature of these cells. 

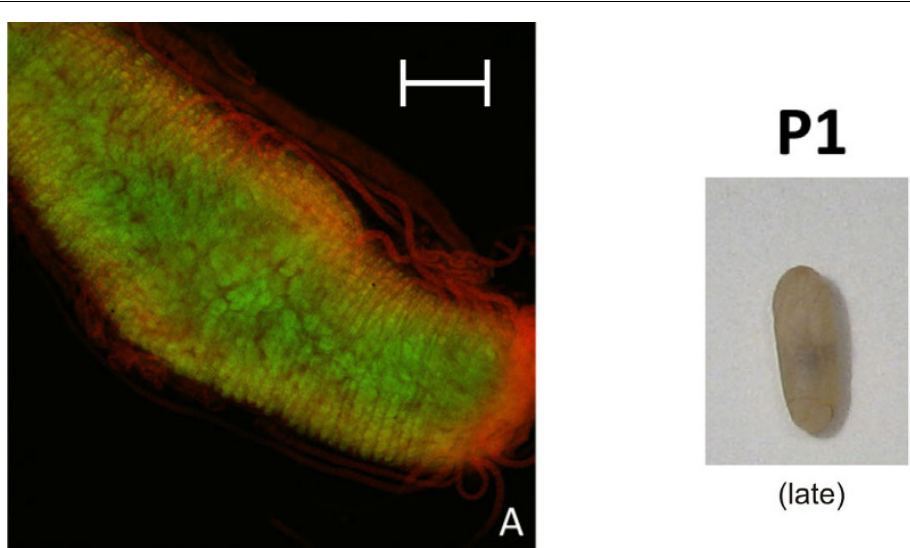

(late)
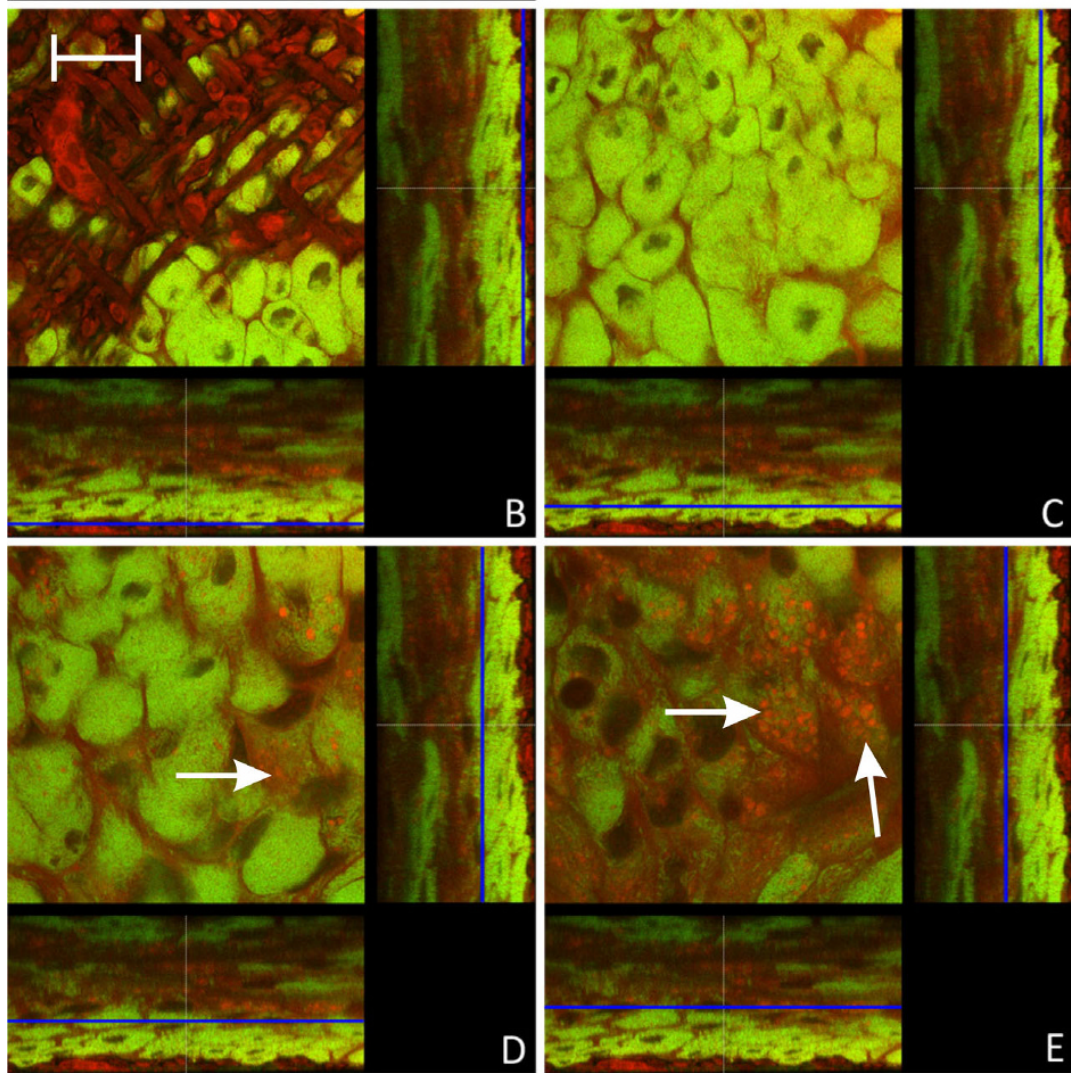

Figure 5 Late stage P1 pupa. Overview (A) and detailed images of different optical sections (B - E) of the midgut of a C. floridanus pupa (P1) at a later stage than the pupa shown in Fig. 4 by confocal laser scanning microscopy (for further information regarding the composition of the figure see legend of Fig. 1). The bacteriocyte layer encloses the entire midgut (C) and the infection of midgut cells other than bacteriocytes (i.e. cells with large and nucleoli-rich nuclei) is increasingly observed (white arrows in D, E). Bacteria-harboring cells are now found in the epithelial layer bordering the gut lumen (E). Green label: The Blochmannia specific probe Bfl172-FITC; red label: SYTO Orange 83. The scale bars correspond to $220 \mu \mathrm{M}(\mathrm{A})$ and $35 \mu \mathrm{M}(\mathrm{B}-\mathrm{E})$, respectively.

\section{Conclusions}

In conclusion, the data presented here demonstrate that there is a permanent presence of bacteriocytes during pupal stages ensuring that the intracellular endosymbionts are not lost during the complex process of metamorphosis which involves a reconstruction of the inner organs of the insect including the digestive tract. During all stages
Blochmannia appears to stay within host cells. Thus the maintenance strategy of Blochmannia during metamorphosis appears to be fundamentally different from that described for Candidatus Erwinia dacicola which shifts from an intra- to an extracellular lifestyle during metamorphosis of the olive fly [24]. Fascinatingly, the strong increase in number of Blochmannia and of 

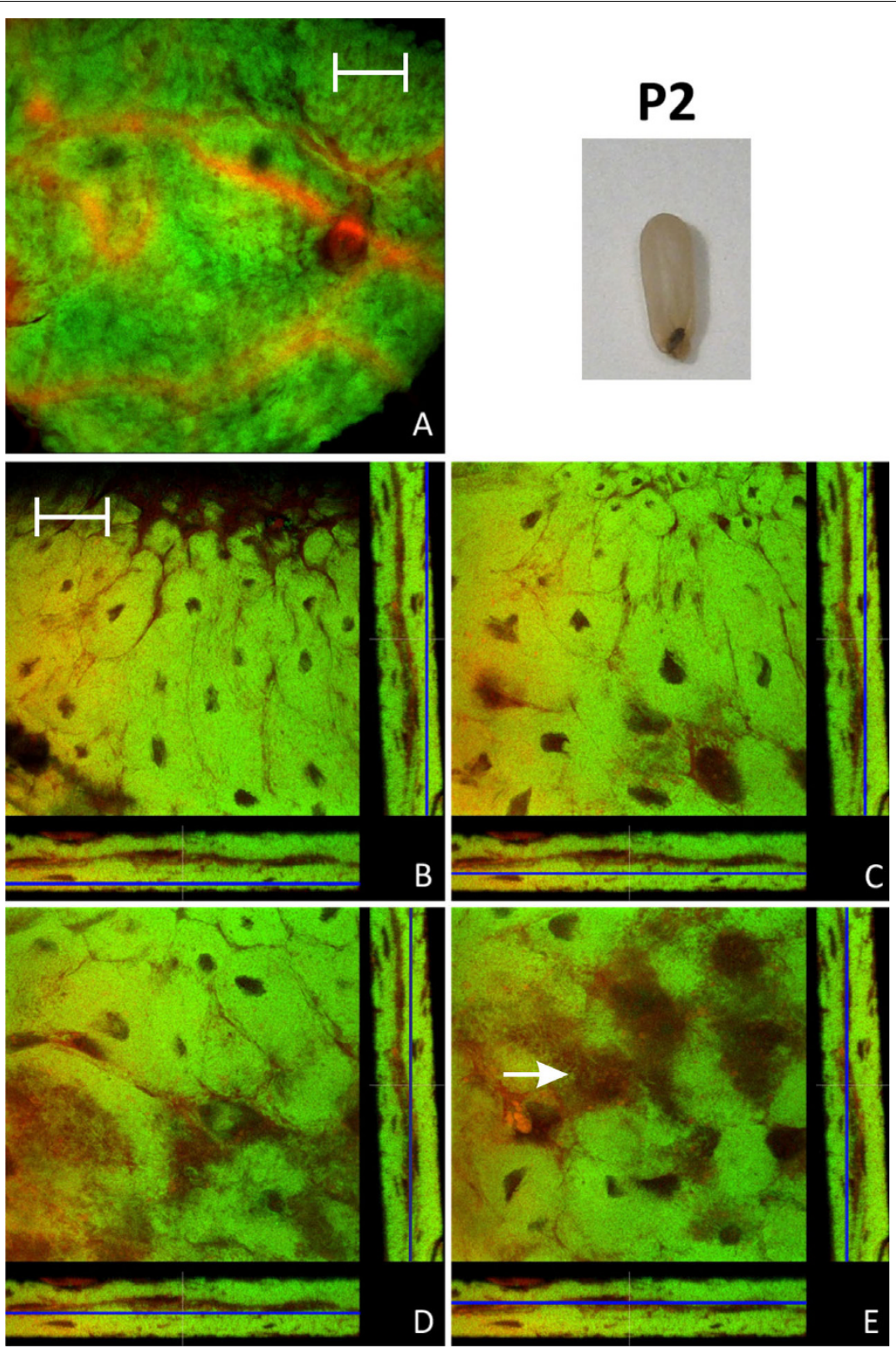

Figure 6 Pupa of stage P2. Overview (A) and detailed images of different optical sections ( $B$ - E) of the midgut of a pupa after excretion of the meconium (P2) by confocal laser scanning microscopy (for further information regarding the composition of the figure see legend of Fig. 1). Virtually all cells of the midgut harbor Blochmannia and the bacteria once more are present in cells with large and nucleoli-rich nuclei (e.g. white arrow in figure part E). Green label: The Blochmannia specific probe Bfl172-FITC; red label: SYTO Orange 83. The scale bars correspond to $220 \mu \mathrm{M}$ (A) and $35 \mu \mathrm{M}(\mathrm{B}-\mathrm{E})$, respectively.

bacteria-bearing cells during metamorphosis transforms the entire midgut into a symbiotic organ which thus resembles a bacteriome known from other insects. These data confirm the implications of previous experiments which showed an important function of the bacterial endosymbionts for individual animals in particular during pupal stages where their metabolic abilities such as nitrogen recycling very likely are relevant for successful completion of metamorphosis $[10,15]$. The fact that aposymbiotic larvae have a strongly reduced capacity to complete metamorphosis further underlines this assumption [13]. The massive presence of the symbionts in young workers, whose task is to care for the brood, is in agreement with previous studies which suggested that the 

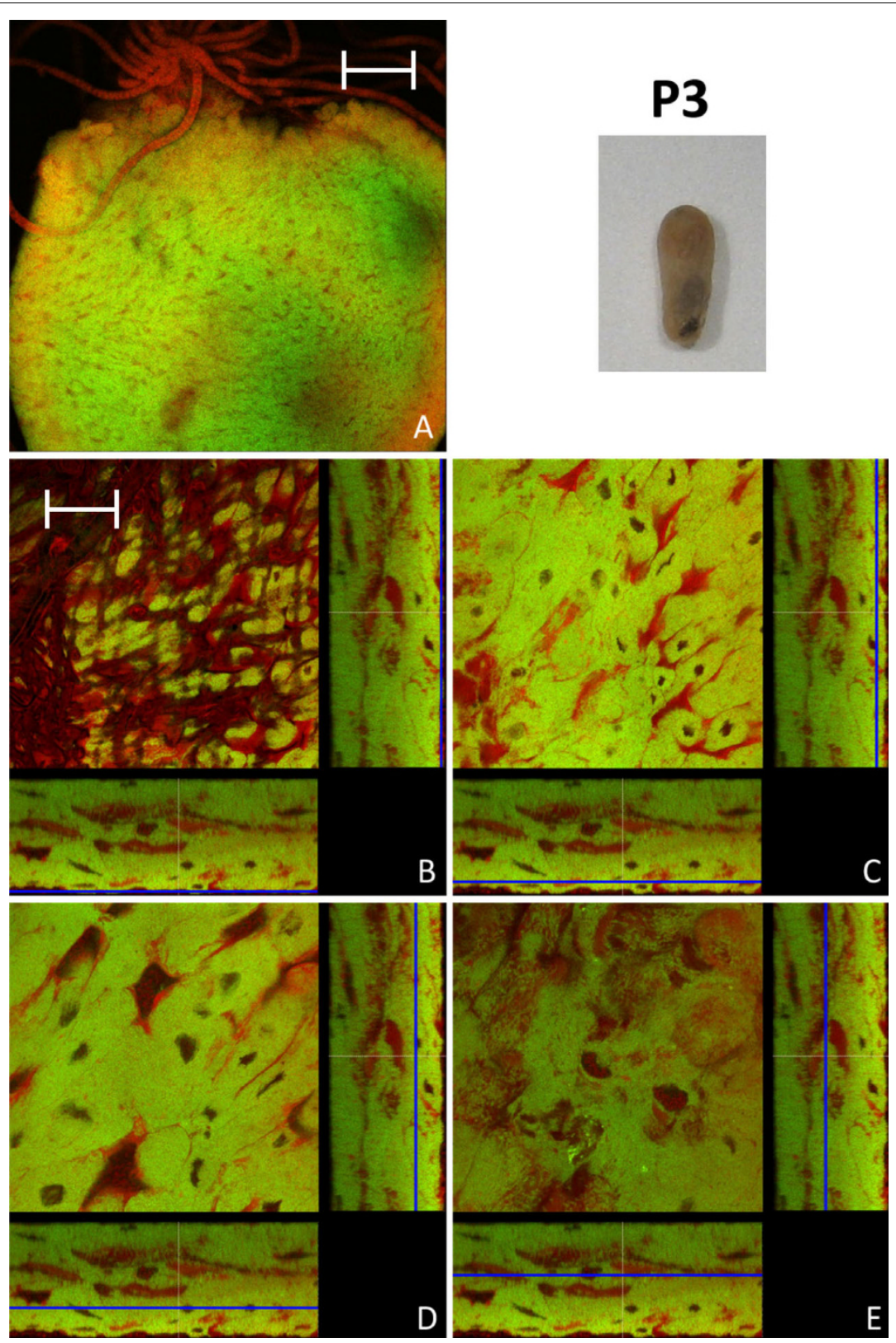

Figure 7 Pupa of stage P3. Overview ( $\mathrm{A}$, red stained Malpighian tubules are visible on the top of the midgut) and detailed images of different optical sections (B - E) of the midgut of a pupa immediately before eclosion (P3) by confocal laser scanning microscopy (for further information regarding the composition of the figure see legend of Fig. 1). In comparison to P2 (see Fig. 6), a slight increase in bacteria-free midgut cells with large nuclei can be observed. Green label: The Blochmannia specific probe Bfl172-FITC; red label: SYTO Orange 83. The scale bars correspond to $220 \mu \mathrm{M}(\mathrm{A})$ and $35 \mu \mathrm{M}(\mathrm{B}-\mathrm{E})$, respectively.

endosymbionts may not only contribute to the high individual needs of these animals but may also play a role in upgrading the nutriment provided to the brood by the young workers $[13,14]$. In the future, it will be important to investigate in detail whether Blochmannia indeed has the capacity to invade epithelial cells, which factors are involved in invasion and whether the lysosomal system may play a role in the control of the intracellular bacteria.

\section{Methods}

Ant culture and stage definition

Camponotus floridanus colonies were kept at $25^{\circ} \mathrm{C}$ with a 12 hour light-dark cycle in artificial nests. The animals were fed twice a week with cockroach pieces (Nauphoeta cinerea), Bhatkar agar [30] and honey water $(50 \% \mathrm{w} / \mathrm{w})$ ad libitum. The colonies used consisted of at least 2,000 workers. The various 

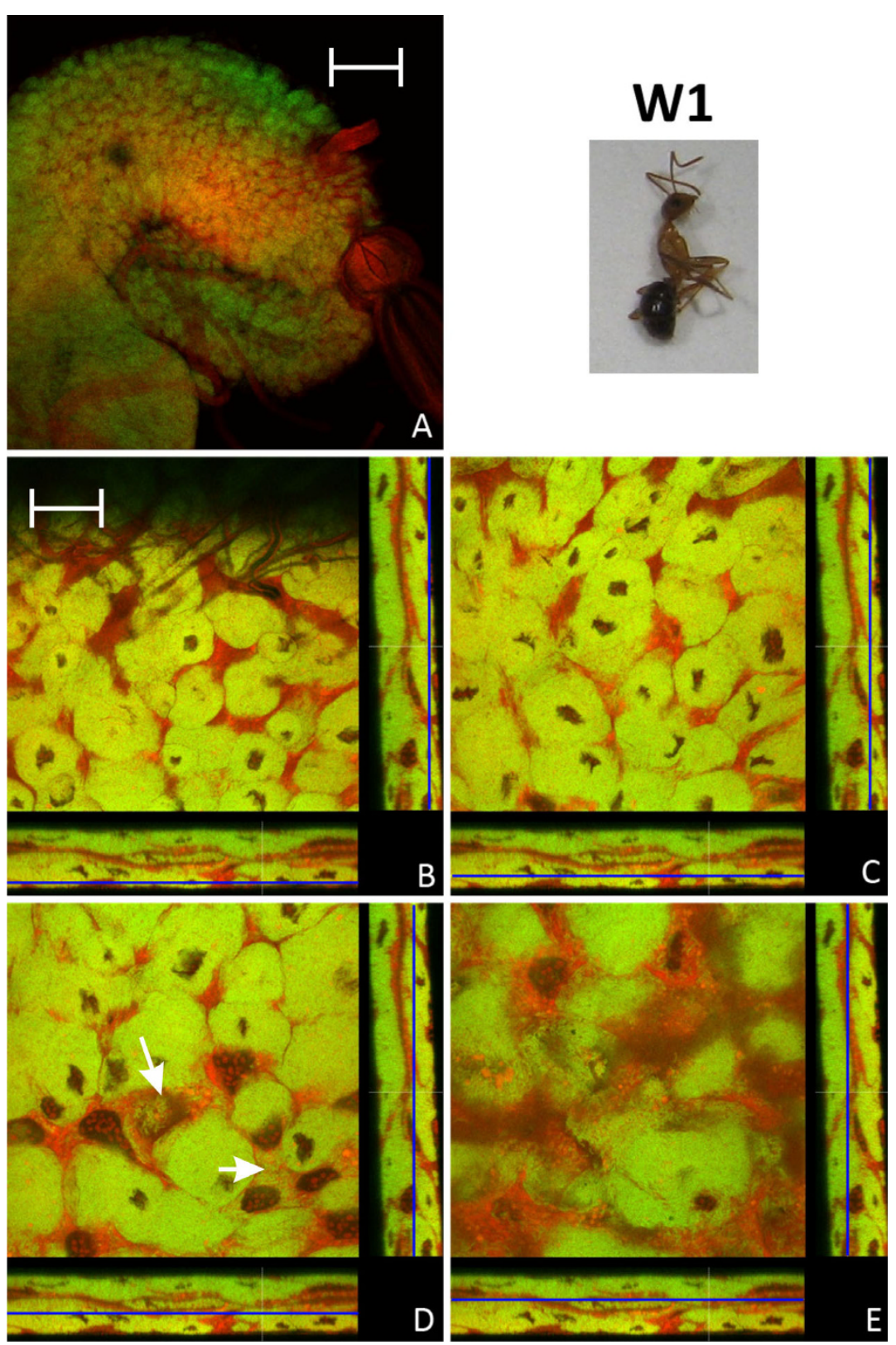

Figure 8 Imago of stage W1. Overview (A) and detailed images of different optical sections (B - E) of the midgut of a young worker shortly after eclosion (W1) by confocal laser scanning microscopy (for further information regarding the composition of the figure see legend of Fig. 1). In the overview (A) the proventriculus can be seen on the right side of the midgut. The number of not-infected cells with larger nuclei is increased in comparison to the late pupae stages (Fig. 7). Still there are bacteria in cells which do not resemble typical bacteriocytes (e.g. white arrows in figure part D). Green label: The Blochmannia specific probe Bfl172-FITC; red label: SYTO Orange 83. The scale bars correspond to 220 $\mu \mathrm{M}(\mathrm{A})$ and $35 \mu \mathrm{M}(\mathrm{B}-\mathrm{E})$, respectively.

developmental stages were defined as follows. L1: small larvae below $2 \mathrm{~mm}$ in size; L2: older larvae, approx. 2 $4 \mathrm{~mm}$ in size; P1: pupae before metamorphosis, enclosed in a pupal cocoon but still larva-like in shape; P2: pupae after metamorphosis, with a worker-like shape but still uncolored; P3: pupae with compound eyes visible as dark spots through the cocoon and cuticle of abdomen already partially melanized, shortly before eclosion; W1: callow workers shortly after eclosion which are not yet completely melanized and show no aggressive behavior; W3: adult workers isolated in queen-less worker-groups for at least 6 months. For confocal analysis five animals of each developmental stage were investigated. 

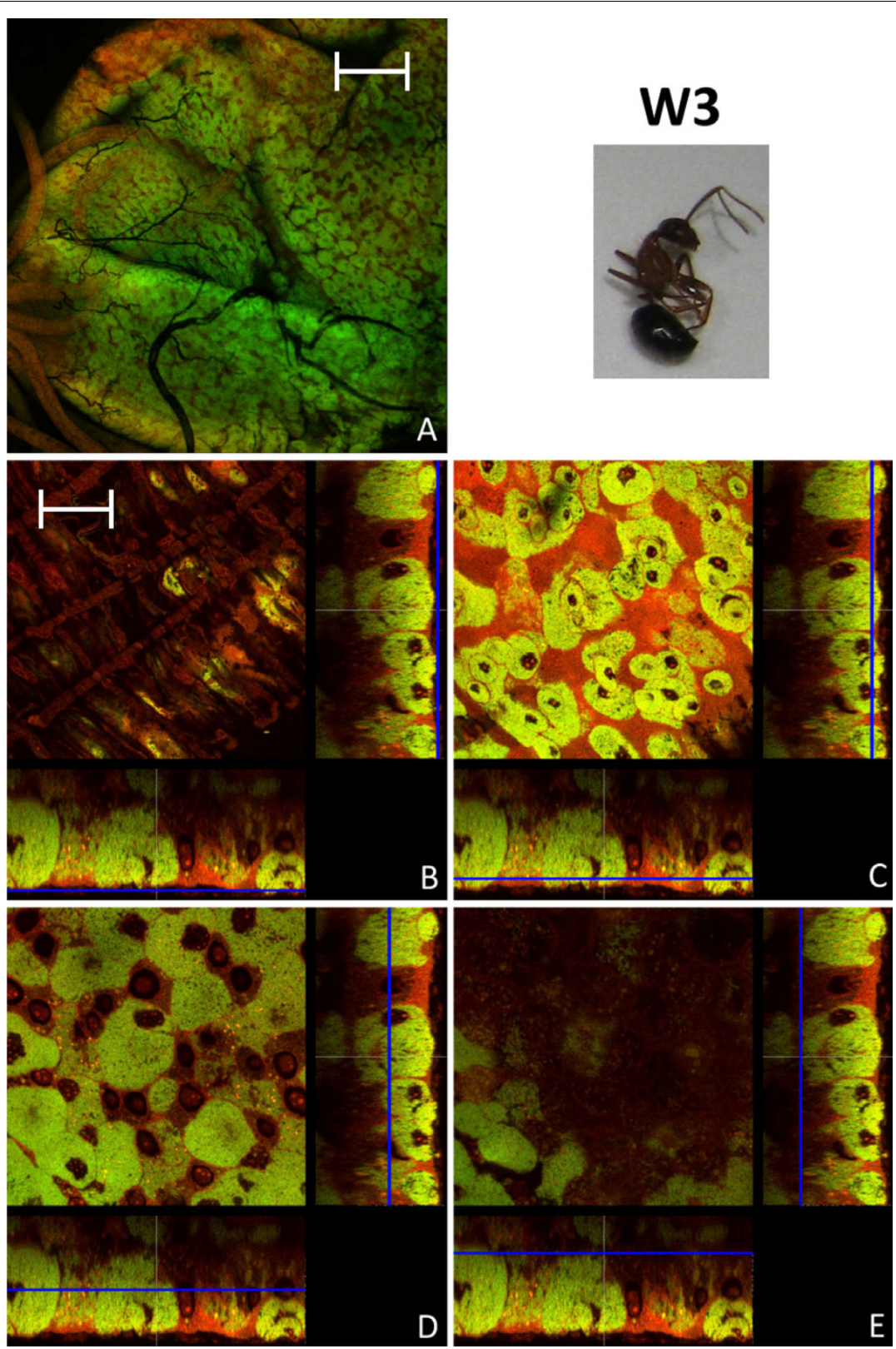

Figure 9 Imago of stage W3. Overview (A) and detailed images of different optical sections (B - E) of the midgut of a worker several months of age (W3) by confocal laser scanning microscopy (for further information regarding the composition of the figure see legend of Fig. 1). The proportion of bacteria-free cells is strongly increased, but still there are many bacteriocytes present. Green label: The Blochmannia specific probe Bfl172-FITC; red label: SYTO Orange 83. The scale bars correspond to $220 \mu \mathrm{M}(\mathrm{A})$ and $35 \mu \mathrm{M}(\mathrm{B}-\mathrm{E})$, respectively.

\section{Confocal laser scanning microscopy (CLSM)}

Midguts were dissected from individuals and gut content washed out in sterile PBS. Subsequently the midgut samples were fixed on microscopic slides and permeabilized as described previously [13]. Hybridization was carried out by default with FITC-labeled oligonucleotide Bfl172 specific for B. floridanus $16 \mathrm{~S}$ rRNA which had been used successfully in a previous study for fluorescent in situ hybridization studies [13]. The probe was labeled with the dye at the 5 'end as described by the manufacturer (Metabion International AG, PlaneggMartinsried, Germany). Alternatively, red fluorescent Cy3-labeled Bfl172 was used. For CLSM with a Leica DMR laser scanning microscope (Leica Microsystems $\mathrm{GmbH}$, Wetzlar, Germany) these labeled oligonucleotides were applied in combination with SYTO Orange 83 (Molecular Probes Inc.) with a concentration of 2.5 $5 \mu \mathrm{M}$ in TE buffer, $\mathrm{pH} 7.4$, resulting in unspecific 

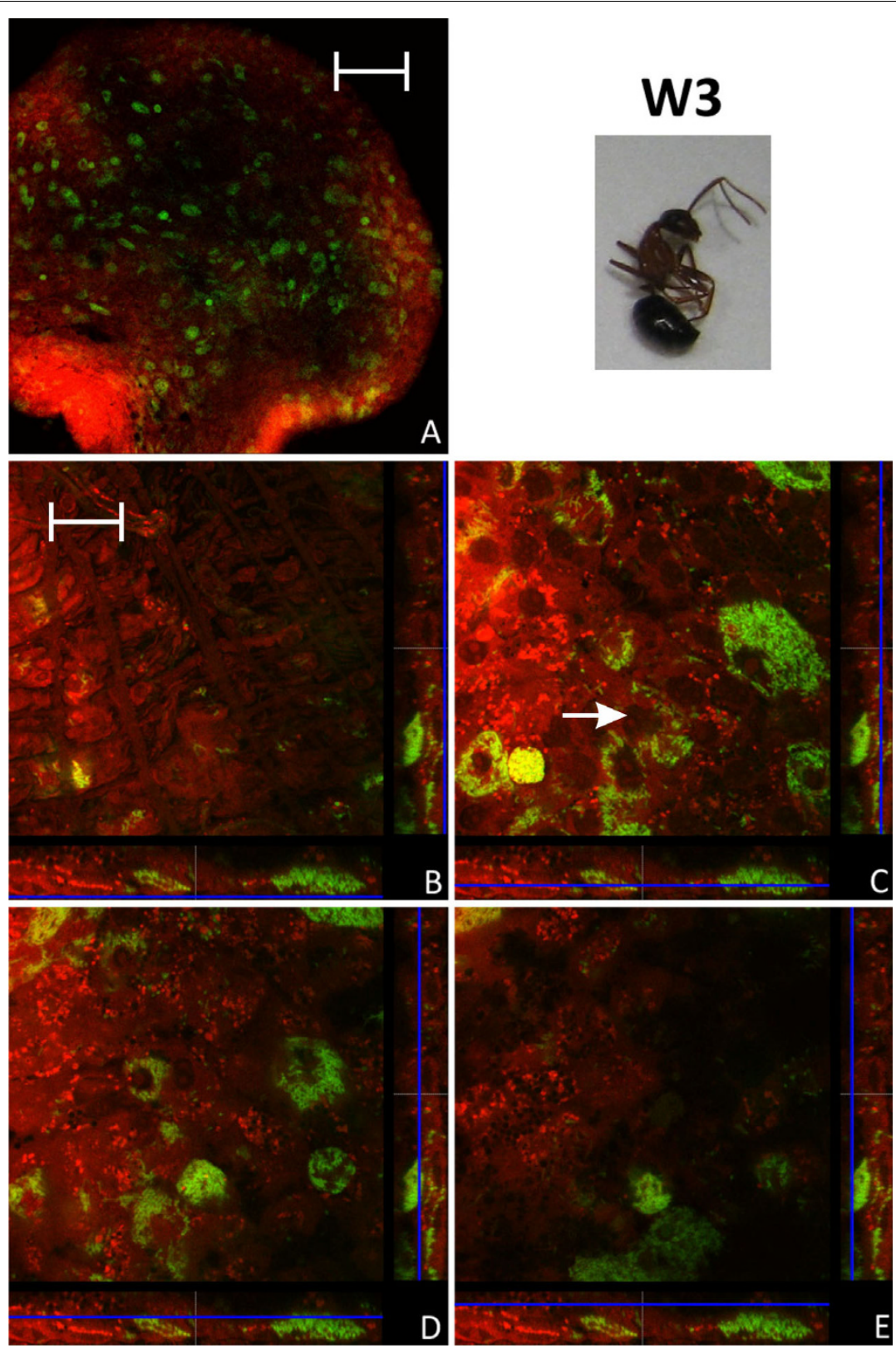

Figure 10 Imago of stage W3. Overview (A) and detailed images of different optical sections (B - E) of the midgut of another worker several months of age (W3) by confocal laser scanning microscopy (for further information regarding the composition of the figure see legend of Fig. 1). The number of bacteriocytes is strongly reduced as compared to the worker (W3) shown in Fig. 9. Bacteria present in other cell types than bacteriocytes can be observed (e.g. white arrow in figure part C). Green label: The Blochmannia specific probe Bfl172-FITC; red label: SYTO Orange 83. The scale bars correspond to $220 \mu \mathrm{M}(\mathrm{A})$ and $35 \mu \mathrm{M}(\mathrm{B}-\mathrm{E})$, respectively.

nucleic acid counterstaining of cytoplasm as well as mitochondria and nuclei after 30 minutes post-FISH incubation and 5 minute washing in TE buffer at room temperature.

For actin-staining $0.5 \mathrm{ng} / \mu \mathrm{l}$ FITC-Phalloidin (Invitrogen Inc.) was used (the B. floridanus specific probe was coupled to $\mathrm{Cy} 3$ instead of FITC in the respective experiments). The dyes were used according to the manufacturers' protocols. Confocal images were analyzed with the Leica Application Suite Advanced Fluorescence Software (Leica Microsystems GmbH, Wetzlar, Germany). Each of the images shown is representative for a series of preparations from the respective host stage with very similar appearances. For the quantification of Blochmannia population densities of ant guts in different larval developmental stages, exemplarily shown 


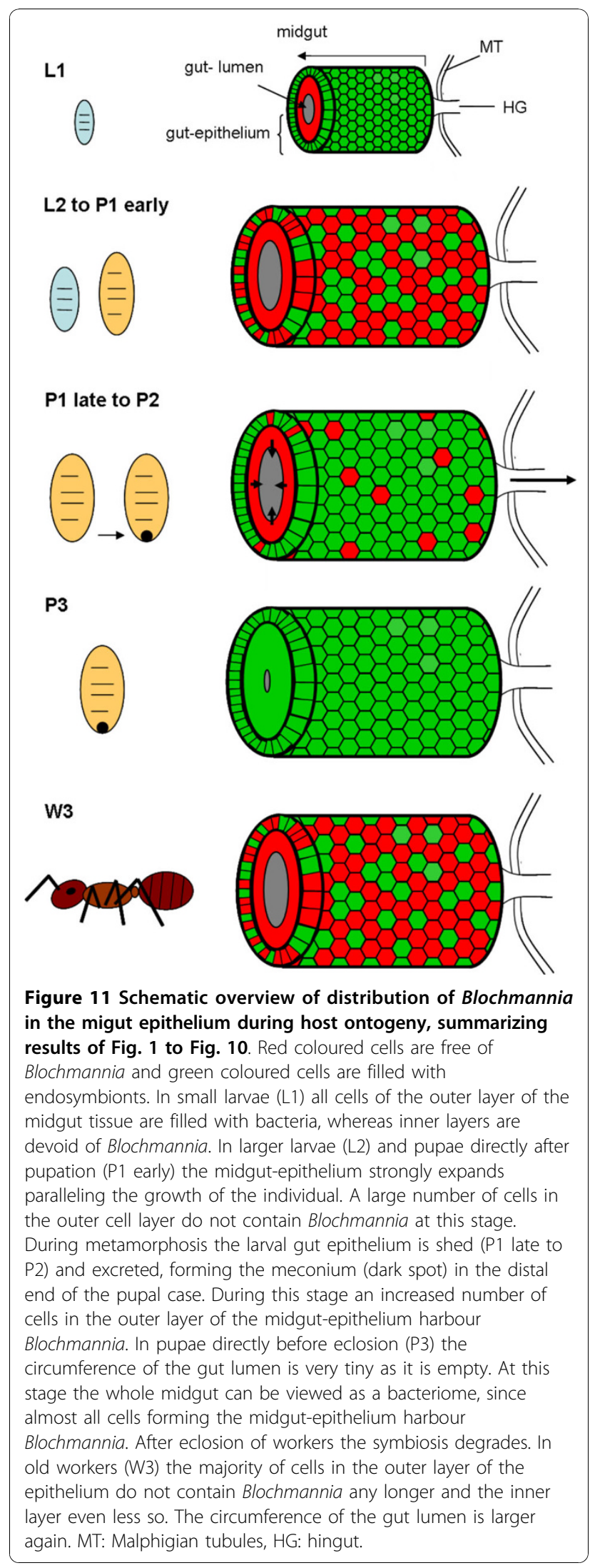

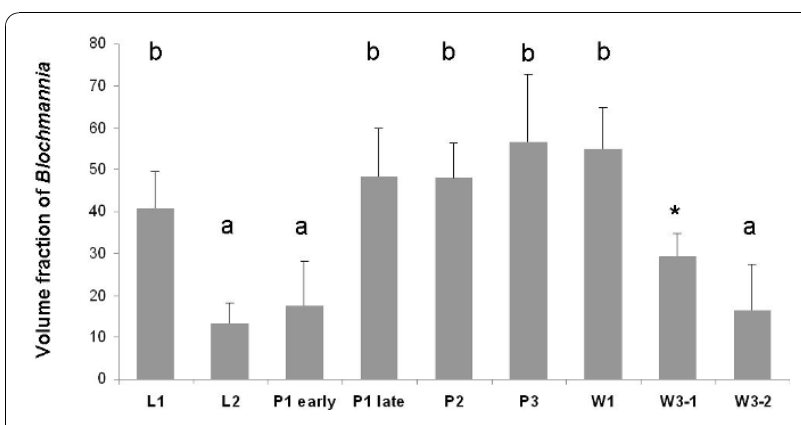

Figure 12 The figure shows volume fractions of Blochmannia symbionts in the midgut tissue of the various developmental stages shown in Fig. 1 to Fig. 10 calculated from the confocal image stacks as described in the Methods section in arbitrary units. The results show the strong relative decrease of Blochmanniabearing midgut cells between $L 1$ and $L 2$, the strong increase in bacteria-infected cells during the P1 stage and the decrease of bacteria-infected cells in adult animals. Standard deviations are shown as vertical bars on top of the columns. Groups differing significantly at the $p<0.05$ level in a Tukey HSD post hoc test are marked with different letters above bars. * W3-1 was not included in the statistical analysis due to small sample size.

in Figure 1 to 10, were calculated as follows: optical sections of gut preparations were recorded by CLSM (see above). Images in the Leica-specific lif file format were opened as ImageJ hyperstacks [31] making use of the LOCI bio-formats plugin (http://loci.wisc.edu/software/ bio-formats). The stack corresponding to the FITC channel was thresholded and binarized. The area fraction of labeled Blochmannia symbionts was thus measured within each confocal slice. Area fractions were collected for each slice of a stack, summed up, and normalized for the number of slices. The resulting value was termed volume fraction of symbionts (Figure 12). Differences in volume fractions among developmental stages were compared using a one-factorial ANOVA, after homogeneity of variances had been confirmed by Levene's test implemented in SPSS 15.0 (SPSS Inc. Chicago, Illinois, USA).

\section{Acknowledgements}

We thank Dagmar Beier and Achim Paululat for critical reading of the manuscript and Adrian Mehlitz for help with confocal microscopy. This work was supported by the SFB567/C2 of the Deutsche Forschungsgemeinschaft and by the EU COST action FA0701 "Arthropod symbioses: from fundamental studies to pest management".

\section{Author details}

'Lehrstuhl für Mikrobiologie, Biozentrum, Universität Würzburg, D-97074 Würzburg, Germany. ${ }^{2}$ Lehrstuhl für Verhaltensphysiologie, Universität Osnabrück, D-49076 Osnabrück, Germany. ${ }^{3}$ QIAGEN GmbH, QIAGEN Str. 1, D40724 Hilden, Germany.

\section{Authors' contributions}

Conceived and designed the experiments: RG, SS and HF. Performed the experiments: SS. Analysed the confocal images: MJF. Wrote the paper: RG and HF. All authors read and approved the final manuscript. 

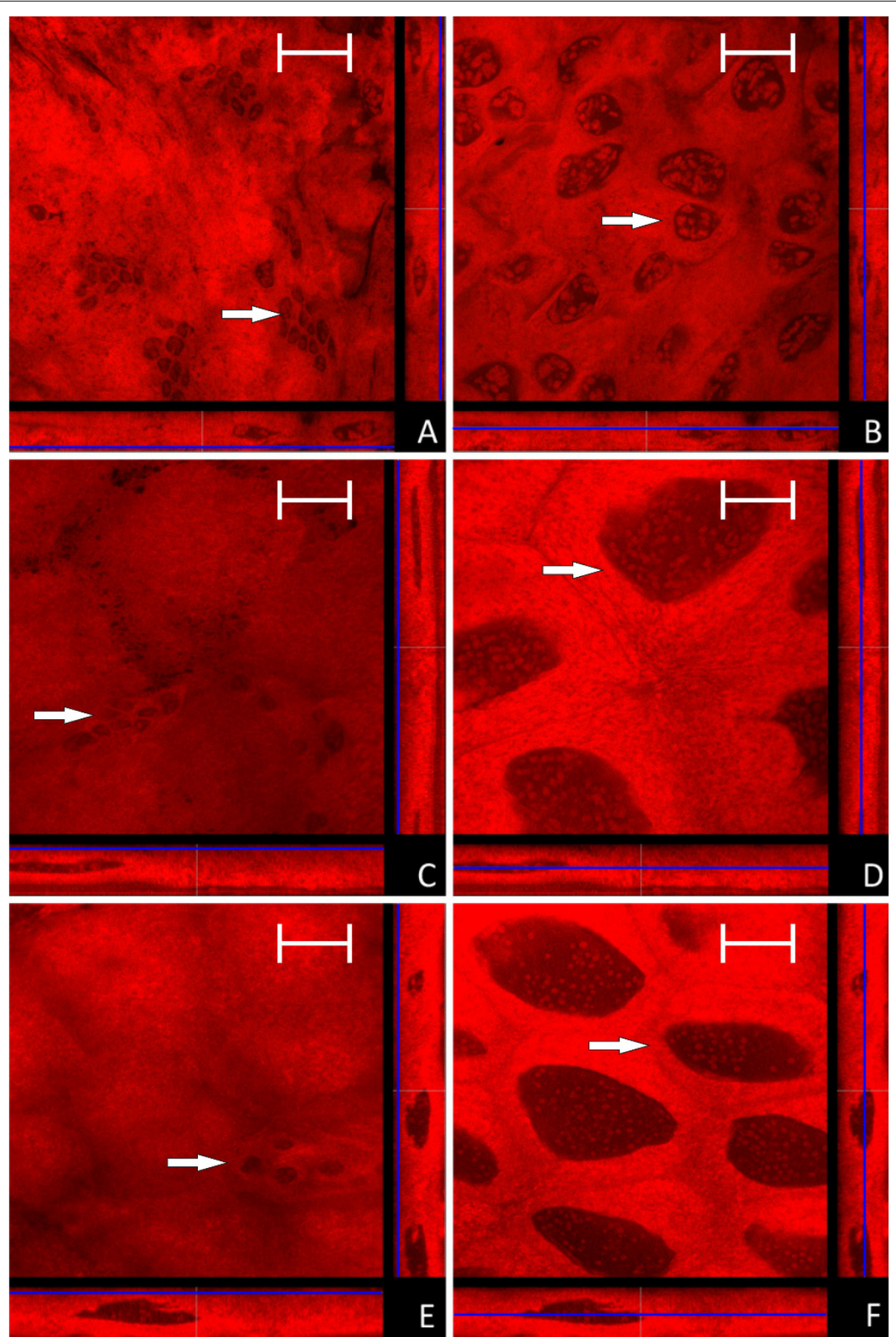

Figure 13 Confocal micrographs of the midgut of larvae and pupae derived from antibiotics treated queens (for further information regarding the composition of the figure see legend of Fig. 1). No Blochmannia specific signal is detectable in any of the preparations. Cells resembling empty bacteriocytes are located as small cell clusters on the outer face of the midgut (marked with a white arrow in figure's parts $A$, C, E), while typical epithelial cells show the characteristic large nuclei (marked with a white arrow in figure's parts B, D, F). A and B: young larvae (L1); C and D: older larvae (L2); E and F: young pupae (P1). Green label: The Blochmannia specific probe Bfl172-FITC; red label: SYTO Orange 83.

The scale bar corresponds to $35 \mu \mathrm{M}$. 
Received: 4 May 2010 Accepted: 1 December 2010

Published: 1 December 2010

\section{References}

1. Buchner P: Endosymbiosis of animals with plant microorganisms. Intersciences Publishers Inc. New York, N.Y; 1965.

2. Baumann P: Biology of bacteriocyte-associated endosymbionts of plant sap-sucking insects. Annu Rev Microbiol 2005, 59:155-189.

3. Wernegreen JJ: Genome evolution in bacterial endosymbionts of insects. Nat Rev Genet 2002, 3:850-861.

4. Sauer C, Dudaczek D, Hölldobler B, Gross R: Tissue localization of the endosymbiotic bacterium "Candidatus Blochmannia floridanus" in adults and larvae of the carpenter ant Camponotus floridanus. Appl Environ Microbiol 2002, 68:4187-4193.

5. Schröder D, Deppisch H, Obermayer M, Krohne G, Stackebrandt E, Hölldobler B, Goebel W, Gross R: Intracellular endosymbiotic bacteria of Camponotus species (carpenter ants): systematics, evolution and ultrastructural characterization. Mol Microbiol 1996, 21:479-489.

6. Moran NA, McCutcheon JP, Nakabachi A: Genomics and evolution of heritable bacterial symbionts. Annu Rev Genet 2008, 42:165-190.

7. Attardo GM, Lohs C, Heddi A, Alam UH, Yildirim S, Aksoy S: Analysis of milk gland structure and function in Glossina morsitans: milk protein production, symbiont populations and fecundity. J Insect Physiol 2008, 54:1236-1242.

8. Dale C, Moran NA: Molecular interactions between bacterial symbionts and their hosts. Cell 2006, 126:453-465.

9. Buchner P: Vergleichende Eistudien. I. die akzessorischen Kerne des Hymenoptereneies. Arch Mikroskop Anat II 1918, 91:70-88.

10. Zientz E, Dandekar T, Gross R: Metabolic interdependence of obligate intracellular bacteria and their insect hosts. Microbiol Mol Biol Rev 2004, 68:745-770.

11. Wernegreen JJ, Kauppinen SN, Brady SG, Ward PS: One nutritional symbiosis begat another: phylogenetic evidence that the ant tribe Camponotini acquired Blochmannia by tending sap-feeding insects. BMC Evol Biol 2009, 9:292.

12. Davidson DW, Cook SC, Snelling RR, Chua TH: Explaining the abundance of ants in lowland tropical rainforest canopies. Science 2003, 300:969-972.

13. Feldhaar H, Straka J, Krischke M, Berthold K, Stoll S, Mueller MJ, Gross R: Nutritional upgrading for omnivorous carpenter ants by the endosymbiont Blochmannia. BMC Biol 2007, 5:48.

14. Zientz E, Beyaert I, Gross R, Feldhaar H: Relevance of the endosymbiosis of Blochmannia floridanus and carpenter ants at different stages of the life cycle of the host. Appl Environ Microbiol 2006, 72:6027-6033.

15. Stoll S, Feldhaar H, Gross R: Transcriptional profiling of the endosymbiont Blochmannia floridanus during different developmental stages of its holometabolous ant host. Environ Microbiol 2009, 11:877-888.

16. Wolschin F, Hölldobler B, Gross R, Zientz E: Replication of the endosymbiotic bacterium Blochmannia floridanus is correlated with the developmental and reproductive stages of its ant host. Appl Environ Microbiol 2004, 70:4096-4102.

17. Richards AG, Brooks MA: Internal symbiosis in insects. Annu Rev Entomol 1958, 3:37-56.

18. Nardon P, Lefevre C, Delobel B, Charles H, Heddi A: Occurence of endosymbiosis in Dryophthoridae weevils: cytological insight into bacterial symbiotic structures. Symbiosis 2002, 33:227-241.

19. Nakabachi A, Shigenobu S, Sakazume N, Shiraki T, Hayashizaki Y, Carninci P, Ishikawa $\mathrm{H}$, Kudo T, Fukatsu T: Transcriptome analysis of the aphid bacteriocyte, the symbiotic host cell that harbors an endocellular mutualistic bacterium, Buchnera. Proc Natl Acad Sci USA 2005, 102:5477-5482

20. Nakabachi A, Koshikawa S, Miura T, Miyagishima S: Genome size of Pachypsylla venusta (Hemiptera: Psyllidae) and the ploidy of its bacteriocyte, the symbiotic host cell that harbors intracellular mutualistic bacteria with the smallest cellular genome. Bull Entomol Res 2010, 100:27-33

21. Braendle C, Miura T, Bickel R, Shingleton AW, Kambhampati S, Stern DL: Developmental origin and evolution of bacteriocytes in the aphidBuchnera symbiosis. PLoS Biol 2003, 1:E21.

22. Nishikori K, Morioka K, Kubo T, Morioka M: Age- and morph-dependent activation of the lysosomal system and Buchnera degradation in aphid endosymbiosis. J Insect Physiol 2009, 55:351-357.
23. Nishikori K, Kubo T, Morioka M: Morph-dependent expression and subcellular localization of host serine carboxypeptidase in bacteriocytes of the pea aphid associated with degradation of the endosymbiotic bacterium Buchnera. Zoolog Sci 2009, 26:415-420.

24. Estes AM, Hearn DJ, Bronstein JL, Pierson EA: The olive fly endosymbiont, "Candidatus Erwinia dacicola," switches from an intracellular existence to an extracellular existence during host insect development. Appl Environ Microbiol 2009, 75:7097-7106.

25. Ohkuma M: Symbiosis of flagellates and prokaryotes in the gut of lower termites. Trends Microbiol 2008, 16:345-352.

26. Sauer C, Stackebrandt E, Gadau J, Hölldobler B, Gross R: Systematic relationships and cospeciation of bacterial endosymbionts and their carpenter ant host species: proposal of the new taxon Candidatus Blochmannia gen. nov. Int J Syst Evol Microbiol 2000, 50:1877-1886.

27. Hakim RS, Baldwin K, Smagghe G: Regulation of midgut growth, development, and metamorphosis. Annu Rev Entomol 2010, 55:593-608.

28. Lambiase S, Fasola M, Diliberto L, Grigolo A, Baccetti B: Bacteriocyte population growth in Blattella germanica. J Submicrosc Cytol Pathol 2003, 35:91-97.

29. Levine B, Klionsky DJ: Development by self-digestion: molecular mechanisms and biological functions of autophagy. Dev Cell 2004, 6:463-477.

30. Bhatkar A, Whitcomb WH: Artificial diet for rearing various species of ants. FI Entomol 1970, 53:229-232.

31. Abramoff MD, Magelhaes PJ, Ram SJ: Image Processing with ImageJ. Biophotonics Int 2004, 11:36-42.

doi:10.1186/1471-2180-10-308

Cite this article as: Stoll et al:: Bacteriocyte dynamics during development of a holometabolous insect, the carpenter ant Camponotus floridanus. BMC Microbiology 2010 10:308.

\section{Submit your next manuscript to BioMed Central and take full advantage of:}

- Convenient online submission

- Thorough peer review

- No space constraints or color figure charges

- Immediate publication on acceptance

- Inclusion in PubMed, CAS, Scopus and Google Scholar

- Research which is freely available for redistribution
Biomed Central 